\title{
Social Interaction Styles, Cognitive-Motivational Variables and Academic Performance in Compulsory Secondary Education: A Predictive Study
}

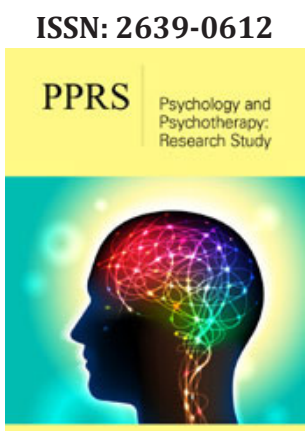

*Corresponding author: Candido J Ingles , Department of Health Psychology, Spain

Submission: 眥 January 21, 2020

Published: 㙉January 29, 2020

Volume 3 - Issue 3

How to cite this article: Candido J Ingles . Social Interaction Styles, Cognitive-Motivational Variables and Academic Performance in Compulsory Secondary Education: A Predictive Study. Psychol Psychother Res Stud. 3(3). PPRS.000562.2020.

DOI: 10.31031/PPRS.2020.03.000562

Copyright@ Candido J Ingles , This article is distributed under the terms of the Creative Commons Attribution 4.0 International License, which permits unrestricted use and redistribution provided that the original author and source are credited.

\author{
Candido J Ingles* \\ Department of Health Psychology, Spain
}

\begin{abstract}
Social interaction styles play an important role psychological and academic adjustment in adolescence. The aim of this study was to predict academic self-concept dimensions, academic goals, and academic performance in a sample of 2,022 Spanish students using as predictors scores on social interaction styles (i.e., aggressive behaviour, prosocial behaviour and social anxiety). Prosocial behavior, aggressive behavior, social anxiety, academic self-concept, and academic goals were measured using self-report measures. Academic performance was measured using school-records. Logistic regression analyses were used to examine the weight predictive of social interaction styles on cognitive-motivational variables and academic performance. Prosocial behavior was a statistically significant and positive predictor for general academic self-concept, verbal self-concept, learning goals, performance goals, and academic performance, whereas aggressive behavior was a statistically significant and negative predictor of general academic self-concept, verbal self-concept and academic performance. Finally, social anxiety was a statistically significant and negative predictor of mathematical self-concept, general academic selfconcept, and learning goals.
\end{abstract}

Keywords: Aggressive behaviour; Prosocial behaviour; Social anxiety; Academic self-concept; Academic performance

\section{Introduction}

The aim of this study is to predict academic performance and several cognitivemotivational variables related such as academic self-concept dimensions and academic goals, using as predictors scores on social interaction styles (i e., aggressive behaviour, prosocial behaviour and social anxiety). Three reasons could justify the present research. Firstly, social interaction styles become more differentiated during adolescence [1], being externalizing problems (e.g., aggressive behaviour), and internalizing problems (e.g., social anxiety and withdrawal) more frequent in this developmental period [2]. Furthermore, positive social interaction styles such as prosocial behaviours are also more frequent during adolescence [3]. In this line, recent research conducted in Spain has revealed high rates of prosocial behaviour, aggressive behaviour, and social anxiety in compulsory secondary education students [4]. Specifically, these authors found that rates of prosocial (17.35\%) and aggressive $(16.12 \%)$ students were significantly higher than the rate of students with social anxiety $(12.06 \%)$. Secondly, the significant increase in of academic failure and early dropout rates in Spanish compulsory secondary education students has made low academic performance one of the main problems faced by Spanish educational system. Data from Spanish Ministry of Education and Science (MEC, 2017) indicated that 31\% of Spanish students had a poor performance in mathematics and $17 \%$ had failed in this subject. Results for performance in the subject of language (Spanish) were similar.

Furthermore, the rate of early dropout $(19 \%)$ was one of the highest in the European Union. Approximately 23\% of Spanish students had not earned a compulsory secondary education diploma, which is necessary to continue in postsecondary enrolment options and/ or the world of work. This worrying phenomenon has led teachers, school psychologists, administrators and researchers to reconsider which factors are involved in the lack of interest 
displayed by students in school tasks [5]. Thirdly, contemporary educational research on classroom learning has established the importance of interpersonal relationships that students established with their peers in predicting success and failure in school settings [6]. Thus, greater knowledge of the interdependence of interpersonal relations, motivational systems, academic selfperceptions, and academic achievement is necessary because it may be used to improve our ability to serve different populations of students [7]. Therefore, studies integrating social interaction styles, cognitive-motivational variables, and academic performance are necessary. In this line, several studies have separately analyzed the relations that academic performance, academic self-concept dimensions, and/or academic goals have with aggressive behaviour [4], prosocial behaviour [8], and social anxiety [9] in samples of Spanish compulsory secondary students. However, the predictive role of these three social interaction styles together on academic performance, academic self-concept domains, and achievement goals in educational environments has not been analyzed yet.

\section{Aggressive behaviour, cognitive-motivational variables, and academic performance}

Previous research has showed that aggressive behaviour is related with a negative general self-concept [10] and a poorer image of themselves as student [11] in adolescence. Using logistic regression analyses, Taylor [12] explored how academic self-concept of middle school students influenced the likelihood of aggressing at school and whether high self-concept exerted a different pattern of influence when threatened. Thus, results of this study suggested that, in general, students with low self-concept in achievement domains are more likely to aggress at school than those with high self-concept [13]. However, there was a small sample of youth who, when they received contradictory information that threatened their self-concept, do aggress. Furthermore, global self-esteem was not found to be predictive of aggression. Regarding to the relationship between aggressiveness and academic goal orientations, it has been found that aggressive behaviour is positively predicted by the desire of gaining positive judgments from other students and negatively predicted by the intention of avoid negative judgments [14]. These results, although not referred to academic goals, point out the importance of social context among aggressive students. Finally, previous evidence has showed that the influence of aggressiveness on academic performance does not seem to be clear. Some studies have found that aggressive behaviour is a statistically negative predictor of academic achievement [15]. However, other studies have showed that aggression had not predictive value for subsequent academic performance [16]. In order to combine both perspectives, a longitudinal study evaluated the influence of academic performance on subsequent aggressive behaviour and the influence of this behaviour on later achievement [17]. Thus, it was found that, although previous academic performance had a negative influence in aggressiveness, this relation was not reciprocal, that is, aggressive behaviour had no influence in subsequent academic achievement. Consistent with these findings, Torregrosa et al. [18] found that aggressive adolescents reported lower levels of academic, social and personal self-perceptions, lower involvement in school tasks, fewer use of learning strategies, higher scores of internal self-attributions for academic failure, academic performance directed to obtain social reinforcement, and lower academic achievement than did their non-aggressive peers.

\section{Prosocial behaviour, cognitive-motivational variables, and academic performance}

Generally, prosocial behaviour and self-concept had been positively related, showing that those students who positively interacted with other classmates had a better general image of themselves [10]. Furthermore, recent empirical studies provided support for academic motivation benefits related to prosocial behaviour. For example, Gilman [19], using a cluster analyses, found that student's group with adaptive motivation (intrinsic motivation and sense of mastery) showed significantly more prosocial behaviours than students' group and low adaptative motivation. In this sense, it has been related positively prosocial behaviour with learning motivation and effort, being motivational orientation a mediate variable between prosocial behaviour and academic yield [20].

The study of the relationship between prosocial behaviour and academic performance has revealed that both variables are positive and reciprocally related [17]. In the same line, Inglés et al. [21], using logistic regression analyses, found that prosocial students of compulsory secondary education had more probability to obtain high performance regarding to non-prosocial classmates, being smaller the rate of prosocial students with school failure. Recent research found that prosocial students reported higher levels of general academic self-concept, verbal academic self-concept [22], learning goals, performance goals [8], learning strategies [23], and an attributional pattern more adaptive compared to non-prosocial classmates [24]. Moreover, the rate of prosocial students with all the passed subjects was significantly higher than the rate of not prosocial peers, while the rate of prosocial students with three or more academic failures was significantly lower than the rate of not prosocial peers [25].

\section{Social anxiety, cognitive-motivational variables, and academic performance}

Previous studies have also revealed that, in general, social anxiety and shyness have been negatively related with global selfworth in primary and secondary school students [26]. Thus, social anxious students perceive themselves as less competent in social and academic settings [27] than classmates without social anxiety. Recent studies have supported a decrease in academic and social self-concept of these anxious students [28,29], creating a vicious circle where students who perceive themselves as less competent in social relationships have more probability to obtain lower academic and social adjustment. On the other hand, in spite of anxiety and distress has related to adoption of maladjusted achievement goals in educative context [30], there are not clear evidences of relation between social anxiety and academic motivation. Thus, some studies have found that students with social anxiety reported lower scores in learning goals and performance goals than students without social anxiety [31].

However, Delgado et al. [27] did not find significant statistical 
differences in achievement goals (learning goals, performance goals and social reinforcement goals) between students with and without social anxiety. The significant deterioration in academic adjustment of adolescents with social anxiety promotes that these students obtain worse performance and a greater risk of premature drop out of school system [32]. Recent research found that students with social anxiety had lower average scores on general academic self-concept, verbal and mathematical self-concept [28], used less adaptive learning strategies and attributed their successes less to external causes and their failures more to internal causes and less to external causes than their peers without social anxiety [27]. In summary, although it has been proved that interpersonal styles play an important role in academic environment, there are few studies where these styles has been included as predictors of psychoeducational variables such as academic self-concept domains, academic goals and academic performance, and when these studies were conducted contradictory results were found. Thus, as indicated by Albers [33], prevention research seems to be important in order not to act when the problem has already appeared but to have an influence before the problem is completely developed. That is the reason for to conduct the present study. The purposes of this research was to analyze the relationship between interpersonal styles and psychoeducational variables using logistic regression models permitting to make inferences about the probability for to present academic adjustment when students have a specific social interaction style, which would allow take some preventive actions. Specifically, the purpose of this study is to predict academic self-concept domains, academic goals, and academic performance in Spanish Compulsory Secondary Education students using as predictors the scores of aggressive behaviour, prosocial behaviour, and social anxiety.

Based on the findings reported above, the following hypotheses were derived:

1. It is expected that aggressive behaviour to be a significant and negative predictor of academic self-concept (general, verbal and math), and academic performance, and a positive predictor of social reinforcement goals.

2. It is expected that prosocial behaviour to be a significant and positive predictor of academic self-concept (general, math and verbal self-concept), learning goals, performance goals and academic performance.

3. It is expected that self-reported social anxiety to be a significant and negative predictor of general academic selfconcept, math and verbal self-concept, and academic performance. However, social anxiety will not be a significant predictor to academic motivation (learning goals, performance goals, and social reinforcement goals).

Furthermore, recent studies have revealed that:

a. Aggressive adolescents present lower levels of attachment to school, characteristic related with a poor academic motivation
[34];

b. Aggressiveness is negatively related to effort to meet achievement goals in school tasks [35]; and

c. Prosocial students are more empathic, oriented toward help and social cooperative behaviours, not toward competition and social comparison, thus, they have more close friends [36], and they are more liked by peers [37], so that it is reasonable to expect that.

4. Aggressive adolescents to have lower likelihood to present learning goals and performance goals than non-aggressive adolescents, and

5. Prosocial students to have lower likelihood to show social reinforcement goals than non-prosocial students.

\section{Method}

\section{Participants}

Cluster random sampling was performed throughout the following geographical areas of the provinces of Murcia and Alicante (Spain): centre, north, south, east and west. Twenty-four middle and high schools from rural and urban areas, 14 public and 6 private, were randomly selected to represent all geographical areas. Each geographical area was represented by an average of two schools. Once the schools were selected, four classrooms were randomly chosen, with approximately 94 students per school. The initial sample consisted of 2,267 students from grades 7 to 10 of Compulsory Secondary Education. Of this total, 116 (5.12\%) were excluded from the study because their answers were incomplete or their parents did not give their informed written consent for them to participate, and a further 129 (5.69\%) were excluded as they were foreign nationals with major gaps in their knowledge of the Spanish language. All the students participated voluntarily. No students declined to participate in this study. The final sample was made up of 2,022 students (51.1\% boys). Ages ranged from 12 to 16 years old ( $M=13.81 ; \mathrm{SD}=1.35)$. Table 1 shows the distribution of the sample according to gender and grade-level. The ethnic composition of the sample was: $88.9 \%$ Spanish, $6.34 \%$ Latin American, $3.37 \%$ European, $.75 \%$ Asian, and .64 \% Arabic. Reported fathers' level of education of the sample was as follows: $10.82 \%$ had an elementary education diploma (grades 1 to 6), 49.86\% had a compulsory secondary education diploma (grades 7 to 10 ), $16.74 \%$ had a high school diploma (grades 11 and 12), 16.03\% completed 3 or more years of college, and $6.55 \%$ did not respond. Mothers' education levels were $11.18 \%$ had an elementary education diploma, $55.84 \%$ had a compulsory secondary education diploma, $13.83 \%$ had a high school diploma, $13.24 \%$ completed 3 or more years of college, and $5.91 \%$ did not respond. Chi-square test was used to determine whether there were distribution differences between the eight Gender $x$ Grade-level groups $\left(X^{2}=4.95 ; \mathrm{p}=.17\right)$. Magnitude analysis confirmed the absence of differences (Phi =.04). 
Table 1: Frequency (and percentage) of participants classified by gender and grade-level.

\begin{tabular}{|c|c|c|c|c|}
\hline & Grade 7 & Grade 8 & Grade 9 & Grade 10 \\
\hline Boys & $309(15.3 \%)$ & $251(12.4 \%)$ & $260(12.9 \%)$ & $213(10.5 \%)$ \\
\hline Girls & $267(13.2 \%)$ & $254(12.6 \%)$ & $242(12.6 \%)$ & $226(11.2 \%)$ \\
\hline Total & $576(28.5 \%)$ & $505(25 \%)$ & $502(24.8 \%)$ & $989(48.9 \%)$ \\
\hline
\end{tabular}

\section{Measures}

\section{Achievement goal tendencies questionnaire (AGTQ; Hayamizu [38])}

The AGTQ is a self-report measure comprising 20 items, designed to measure three academic goal tendencies: Learning Goals, assessing tendencies among individuals who are concerned with increasing their competence; Social Reinforcement Goals, assessing the tendency of students wishing to learn in order to obtain approval or avoid rejection by parents and teachers; and Performance Goals, assessing the tendency of students to learn because they want to get good grades and advance in their studies. Students rate each item on a 5 -points Likert scale $(1=$ never; 5 always). Several studies have supported reliability and validity evidence of scores on the AGTQ in samples of American [38] and Spanish students [4]. In the present research, internal consistency coefficients of scores on the AGTQ were: Learning Goals (.79), Social Reinforcement Goals (.74), and Performance Goals (.71).

\section{Self-description questionnaire II (SDQ-II; Marsh, [39])}

The SDQ-II is a 102-item instrument for adolescents aged 12 to 18 . It is designed to measure 11 self-concept factors, assessing three academic scales (Math, Verbal and General School) and seven non-academic scales (Parent Relation, Physical Abilities, Physical Appearance, Same Sex Relations, Opposite Sex Relations, Emotional Stability and Honesty-Trustworthiness). The eleventh scale is a measure of general self-esteem. The items are scored with a 6-points Likert scale ( 1 =false; $6=$ true). Each scale is composed of 8 or 10 items. Several studies have found adequate reliability and validity evidence of scores on the SDQ-II in samples of Australian [39], American [40] and Spanish students [21]. In the present study adequate internal consistence coefficients (alpha's Cronbach) were obtained for scores on General Academic self-concept (.89), Math self-concept (.91), and Verbal self-concept (.84).

\section{Academic performance}

Academic performance was measured from school records in Math, English and Spanish. Grades in Spanish and mathematics were registered from 0 to 10 . General academic achievement was codified as the average grade achieved in Mathematics, English and Spanish.

\section{Teenage inventory of social skills (TISS; Inderbitzen [41])}

The TISS is a self-report measure comprising 40 items, designed to assess social competence with peers in adolescence by means of two scales: Prosocial Behavior and Antisocial Behavior. The items are scored in a 6-points response scale $(1=$ don't describe me; $6=$ totally describe me). Inderbitzen [41] informed satisfactory internal consistency and temporal stability coefficients for two subscales. The Spanish version of TISS was conducted by Inglés [42]. These authors confirmed the two-factor structure of scores on the TISS in a sample of adolescents using confirmatory factor analysis. The internal consistency coefficients (alpha's Cronbach) were adequate: .89 (Prosocial Behaviour), and .84 (Antisocial Behaviour). Similar coefficients were obtained in this study: .90 (Prosocial Behaviour), and .82 (Antisocial Behaviour).

\section{Social phobia and anxiety inventory (SPAI; Turner [43])}

The SPAI is composed for 45 items that measure social phobia and agoraphobia by means of two scales. The Social Phobia subscale contains 32 items, 17 of which they measure social anxiety in different situations as the presence from strangers, figures of authority, people of opposite sex and people in general. The Agoraphobia subscale contains 13 items. Item are scored according to a 7-points Likert scale (1=never; 7=always). In this study were used scores of the Social Phobia subscale, since previous studies have demonstrated that this is the score more appropriate to detect to young people with social anxiety [44]. The empirical evidence has demonstrated that the psychometric properties of SPAI are satisfactory in American [45] and Spanish adolescents [46]. The internal consistency coefficient of the Social Phobia subscale score in this study was .95 .

\section{Procedure}

Self-report measures were answered collectively in the classroom. Research assistants informed the students that their participation was strictly voluntary. The questionnaires were distributed with instructions and answer sheets. The instructions were read aloud, stressing the importance of answering each question. Research assistants supervised each administration of the questionnaires. The order of presentation of the scales was randomly established for each group of students. The average administration time was: 15-20 minutes for SPAI, 10-15 for TISS, 5-10 for AGTQ, and 15-20 for SDQ-II.

\section{Statistical analyses}

To evaluate the predictive capacity of prosocial behaviour, aggressive behavior, and social anxiety on scores of achievement goals, academic self-concept domains, and academic performance, multiple logistic regression analyses were used. Logistic modeling is ideally suited for this task [47]. Logistic modeling allows one to estimate the probability that a particular outcome, event or dependent variable (e.g.academic success) will occur in the presence of a factor independent variable (e.g., prosocial behaviour). Logistic regression models are used instead of ordinary linear models when 
dependent variables are binary (e.g., academic success vs. academic failure). Moreover, logistic regression statistics are more powerful than discriminant analysis when normality and homoscedasticity requirements are not fulfilled [47].

In this study, the grade point average were dichotomized as high performance (HP) and low performance (LP); HP was determined to apply if the students achieved an average grade of 7 or above and LP if the students achieved an average grade lower than 5.99 in point average. The social anxiety was also dichotomized using the clinical cut point proposed by Olivares et al. [44] for Social Phobia subscale in Spanish adolescents (raw score=100), while prosocial behaviour, aggressive behaviour, academic goals and academic selfconcept domains were dichotomized as high (more than quartile 4) and low (smaller than quartile 1), since these variables were measured using educational scales without clinical cut-offs. Logistic regression analyses produce an effect size estimate called an odds ratio (OR). If OR is greater than 1 , then the dependent variable is more likely to happen when the factor or independent variable is present. If OR is less than 1 , then dependent variable is less likely to happen when independent variable is present. The Table 2 shows the OR derived from logistic regression models for explaining the probability to obtain high self-concept, high achievement goals and high academic performance.

Table 2: Results derived from the logistic regression for the probability of achieving high academic self-concept, high achievement goals and general academic success.

\begin{tabular}{|c|c|c|c|c|c|c|}
\hline Predictor & B & S. E & Wald & $\mathbf{P}$ & OR & CI 95\% \\
\hline \multicolumn{7}{|c|}{ General academic self-concept } \\
\hline PB & 0.99 & 0.26 & 14.87 & 0 & 2.69 & $1.62-4.44$ \\
\hline $\mathrm{AB}$ & -0.8 & 0.26 & 9.56 & 0 & 0.45 & $0.27-0.75$ \\
\hline SA & -0.81 & 0.39 & 4.34 & 0.04 & 0.44 & $0.21-0.95$ \\
\hline \multicolumn{7}{|c|}{ Verbal self-concept } \\
\hline PB & 1.07 & 0.25 & 18.51 & 0 & 2.92 & $1.79-4.76$ \\
\hline $\mathrm{AB}$ & -1.34 & 0.25 & 28.82 & 0 & 0.26 & $0.16-0.43$ \\
\hline \multicolumn{7}{|c|}{ Mathematical self-concept } \\
\hline SA & -1.04 & 0.38 & 7.54 & 0.01 & 0.35 & $0.17-0.74$ \\
\hline \multicolumn{7}{|c|}{ Learning goals } \\
\hline PB & 1.41 & 0.24 & 33.57 & 0 & 4.1 & $2.54-6.61$ \\
\hline SA & -0.75 & 0.37 & 4.07 & 0.04 & 0.47 & $0.23-0.98$ \\
\hline Constant & -0.65 & 0.17 & 14.3 & 0 & 0.52 & \\
\hline \multicolumn{7}{|c|}{ Performance goals } \\
\hline PB & 1.55 & 0.26 & 36.39 & 0 & 4.69 & $2.84-7.75$ \\
\hline Constant & -0.94 & 0.19 & 25.18 & 0 & 0.39 & \\
\hline \multicolumn{7}{|c|}{ Social reinforcement goals } \\
\hline $\mathrm{AB}$ & 0.77 & 0.25 & 9.43 & 0 & 2.17 & $1.32-3.56$ \\
\hline \multicolumn{7}{|c|}{ Academic performance } \\
\hline PB & 0.78 & 0.23 & 11.24 & 0 & 2.18 & $1.38-3.45$ \\
\hline $\mathrm{AB}$ & -0.68 & 0.23 & 8.44 & 0 & 0.5 & $0.32-0.80$ \\
\hline Constant & -0.83 & 0.2 & 17.1 & 0 & 0.44 & \\
\hline
\end{tabular}

Note: PB: Prosocial Behaviour; AB: Aggressive Behavior; SA: Social Anxiety; B: Regression Coefficient; SE: Standard Error; P: Probability; OR: Odds Ratio; CI: Confidence Interval to 95\%.

\section{Results}

\section{Social interaction styles and academic self-concept domains}

The models generated for the dependent variables high general academic self-concept, high verbal self-concept and high mathematical self-concept allowed a correct estimation of $64.7 \%$,
$67.1 \%$ and $55.9 \%$, respectively, with the predictors prosocial and aggressive behaviour and social anxiety (academic self-concept model), prosocial and aggressive behaviour (verbal self-concept model), social anxiety (mathematical self-concept model) forming part of the equations. The adjustment values (Nagelkerke's $\mathrm{R}^{2}$ ) of the models for high self-concept varied between .04 and .21 . The odds ratio (OR) revealed that the probability of high academic self- 
concept was 2.69 times higher in prosocial adolescents that in nonprosocial adolescents, .45 times lower in aggressive adolescents that in non-aggressive adolescents, and .44 times lower in social anxious adolescents that in nonsocial anxious classmates. In other words OR showed that the probability of high general academic self-concept was $169 \%$ higher in prosocial students, 55\% lower in aggressive students, and 56\% lower in students with social anxiety. Furthermore, the OR revealed that the probability of high verbal self-concept was $192 \%$ higher in prosocial students and $74 \%$ lower in aggressive students (Table 2). Regarding to mathematical self-concept model, the OR indicated that the probability of high mathematical self-concept was $65 \%$ lower in adolescents with social anxiety.

\section{Social interaction styles and achievement goals}

Logistic models generated for scores of learning goals, performance goals and social reinforcement goals (dependent variables) allowed a correct estimation of $66.2 \%, 68.3 \%$ and $58.7 \%$, respectively, with the predictors prosocial behaviour and social anxiety (learning goals model), prosocial behaviour (performance goals model), aggressive behaviour (social reinforcement goals model) forming part of the equations. Nagelkerke's $\mathrm{R}^{2}$ estimated a model adjustment between .05 and .17 . The OR revealed that the probability to present high learning goals was $310 \%$ higher in prosocial students, and 53\% lower in students with social anxiety (Table 2). Furthermore, the OR revealed that the probability of highperformance goals was 4.69 times higher in prosocial adolescents that in non-prosocial adolescents, so, the probability of to have high performance goals was 369\% higher in prosocial students. Finally, the OR indicated that the probability of high social reinforcement goals was $117 \%$ higher in aggressive students (Table 2).

\section{Social interaction styles and academic performance}

The model generated for high academic performance allowed a correct estimation of $66.8 \%$, with scores of prosocial and aggressive behaviour forming part of the equation (Table 2). The value of Nagelkerke's $\mathrm{R}^{2}$ of the model was .08 . The OR revealed that the probability of high general academic performance was $118 \%$ higher in prosocial students and 50\% lower in aggressive students.

\section{Discussion}

The purpose of this study was to analyze the predictive role of social interaction styles (aggressive behaviour, prosocial behaviour, and social anxiety) on academic self-concept domains, goal orientations, and academic performance in a sample of Spanish compulsory secondary education students. As it was expected, aggressive behaviour was as a risk factor for high academic selfconcept, both general and verbal. However, it was not a predictor for math self-concept. The absence of influence of aggressive behaviour on math self-concept could be explained since aggressive students' self-concept profiles have been identified as low for verbal ability and general school but not for maths ability [48]. According to previous studies [14], and providing support for the first hypothesis, aggressive style was also a risk factor for high academic performance, showing the increased probability of not reaching academic achievement when students present this interaction style. Regarding to academic goals, the results of the present study showed that aggressive style was a positive predictor of social reinforcement goals. The predictive value of aggressive behaviour on social reinforcement goals could be related to the search of approval in aggressive students. As it was reported by Ryan [13], the gain of positive judgements was a predictor of aggressive behaviour, showing that social context was important for aggressive students. As the scale used to assessed social reinforcement goals measured mostly the gain of a positive judgment by peers and teachers it could be possible that aggressive students were motivated to study just to obtain a positive view from others.

Nevertheless, contrary to hypothesized, aggressive students did not present more risk to obtain lower learning and performance goals in comparison to non-aggressive students. This finding indicates that despite the aggressive students maintain worse attitude towards the school [34] and less effort in scholastic tasks [35] their asocial behaviour do not predict directly learning and performance goals. However, Morrison [49] found that depending on mediator variables aggressive students have higher or lower self-concept. Consequently, the control of moderating and mediator variables (gender, self-concept, academic attribution, performance) could be an adequate strategy to clarify the predictive role of aggressive behaviour to academic motivation. As previous research has found, prosocial behaviour was a positive predictor of high general academic self-concept, and high verbal self-concept. However, prosocial behaviour was not a predictor for mathematical self-concept, which could be explained by the fact the self-concept examined in previous studies was a self-concept general and selfesteem [9], and that general self-concept is partially link to specific math self-concept. Thus, the effect of prosocial style in the way of individuals perceived them as students could depend on the study area or subject. Findings regarding to prosocialness as a predictor of learning goals and performance goals were also consistent with previous studies [18]. Prosocial students usually are more motivated intrinsically and more oriented toward mastery of school tasks and improve of their performance, having more likelihood to obtain a better academic achievement [20].

However, results of this study did not support the hypothesis what prosocialness is a negative predictor of social reinforcement goals. This result could be explained by the fact that social reinforcement goals are not a goal orientation representative in the prosocial student's group [36]. Consistently to these findings, prosocialness was a positive predictor of academic achievement. Prosocial students showed $118 \%$ more probability to obtain high academic performance than non-prosocial students. Thus, results of this study support again the relevance of prosocial characteristics in academic adjustment of students. In addition to the potential predictive of prosocial and aggressive behaviour, this study also examined weight predictive of social anxiety on cognitive-motivational variables and academic performance. Social anxiety was a significant predictor in three of seven models created, revealing that this style of social interaction is less relevant for the prediction of verbal self-concept, social reinforcement goals and 
performance goals and academic performance than aggressive and prosocial behaviour styles.

Mixed support was found for social anxiety predicting selfconcept and achievement goals. The hypothesis that social anxiety would predict negatively academic self-concept was confirmed, supporting the findings found by Delgado et al. [28]. Thus, students with self-reported social anxiety informed 56\% and 65\% lower likelihood to maintain high general academic self-concept and high math self-concept, respectively. These results suggest that adolescents with difficulties in their social relations may not just influence negatively in social self-efficacy and general self-concept, otherwise it could affect directly in self-image of adolescents as a student. Thus, according to Fordham [50], these results suggest the importance of social self-efficacy in self-worth increase as children grow up, becoming more strongly linked to anxiety and other internalizing problems in adolescence. Although social anxiety was hypothesized as independent factor to achievement goals, social anxiety tended to predict learning goals. Students with social anxiety obtained 53\% lower probability to maintain high levels or learning goals. These results are consistent with prior findings Cantwell [31], which found that students with social anxiety felt a great discomfort in group of learning, being higher levels discomfort in groups negatively related to learning and performance goals. In the same line, Delgado et al. [51] found that socially anxious students reported lower interest towards school and academic success, even though had not found this difference in achievement goals. Social anxiety was not included in academic performance model, revealing a lower predictive power respect to prosocial and aggressive styles. This finding could be explained by the fact that previous findings did not introduce other social interaction styles in their predictive models, the assessment was conducted with clinic interviews, and some studies used a retrospective methodology. Moreover, as reported by Strahan [52], is possible that different kinds of social functioning may be found in groups of socially anxious students. They proposed a group of individuals which in spite to show great levels of anxiety, they can perform properly, since they automated their anxious thoughts for consume only a small amount of processing capacity. Therefore, it would be interesting and necessary to go into this differentiation in depth in adolescent population with social anxiety, and to examine if there are differences in their academic adjustment.

The interpretation of these results must bear in mind certain limitations that should be resolved for future investigations. As it was previously commented, further research should consider the meditational role of other academic variables [53]. In this sense, it would be interesting to assess if there are mediating variables in the relation between interpersonal styles and academic self-concept, academic goals and academic performance and if so introduce them in the models to provide more adjusted predictions. Furthermore, the design employed in this study was cross-sectional, not allowing to make causal inferences, so that future research should include a longitudinal design and to generate causal models using structural equation modeling $[54,55]$. In summary, the results of this study support previous conclusion that students' relationship with peers are potentially important for understanding their levels of academic self-concept, achievement goals and academic performance [56]. These results may be useful for understanding the contribution of social behaviour in the maintenance of good academic adjustment. Findings could be used for teachers and school psychologists as an empirical research base to plan effective preventive actions, which should include a screening of students interpersonal tendency of interaction and a program to improve their academic functioning in the psychoeducational variables proposed by the logistic models.

\section{References}

1. Rubin KH, Bukowski W, Parker J (2006) Peer interactions, relationships, and groups. In: Eisenberg N, Damon W, Lerner RM (Eds,). Handbook of Child Psychology: Social, emotional, and personality development, Wiley, New York, USA, pp. 571-645.

2. Bukowski WM, Brendgen M, Vitaro F (2007) Peers and socialization: Effects of externalizing and internalizing problems. In Grusec JE, Hasting PD (Eds.), Handbook of socialization, Guilford Press, New York, USA, pp. 355-381.

3. Eisenberg N, Fabes RA, Spinrad TL (2006) Prosocial development. In: Eisenberg N, Damon W, Lerner RM (Eds.), Handbook of child psychology: Social, emotional, and personality development ( $6^{\text {th }}$ edn), Wiley, New York, USA, 3: 646-718.

4. Inglés CJ, Monteagudo MMC, Delgado B, Torregrosa MS, Redondo J, et al. (2008) Prevalence of aggressive behaviour, prosocial behaviour, and social anxiety in a sample of Spanish adolescents: A comparative study. Journal for the Study of Education and Development 31(4): 449-461.

5. Elliot A, Dweck C (2005) Handbook of competence and motivation. Guilford, New York, USA.

6. Wentzel K, Looney L (2007) Socialization in school settings. In: Grusec JE, Hastings PD (Eds.), Handbook of socialization: Theory and research, Guilford Press, New York, USA, pp. 382-403.

7. Miller G, Reynolds WM (2003) Future perspectives in educational psychology. In: Reynolds WM, Miller GE, Weiner IB (Eds.), Handbook of psychology: Educational psychology, Wiley, New York, USA 3: 609-630.

8. Inglés CJ, González MAE, Valle A, Fernández GJM, Esteban RC (2011) Prosocial behavior and academic motivation in Spanish high school students. Universitas Psychologica 10(2): 451-465.

9. Calvo AJ, González R, Martorell MC (2001) Variables related to prosocial behaviour in childhood and adolescence: Personality, self-concept and gender. Journal for the Study of Education and Development 93: 95-111.

10. Garaigordobil M, Dura A, Pérez JI (2005) Psychopathological symptoms, behaviour problems and self-concept/self-esteem: A study with adolescents from 14 to 17 years. Anuario de Psicología Clínica y de la Salud 1: 53-63.

11. Taylor LD, Davis Kean P, Malanchuk O (2007) Self-esteem, academic selfconcept, and aggression at school. Aggress Behav 33(2): 130-136.

12. Torregrosa MS, Inglés CJ, Fernández GJM (2011) Aggressive behavior as a predictor of self-concept: A study with a sample of spanish compulsory secondary education students. Psychosocial Intervention 20(2): 201212.

13. Ryan AM, Shim SS (2008) An exploration of young adolescents' social achievement goals and social adjustment in middle school. Journal of Education 100(3): 672-687.

14. Loveland JM, Lounsbury JW, Welsh D, Buboltz W (2007) The validity of physical aggression in predicting adolescent academic performance. Br J Educ Psychol 77(1): 167-176.

15. Caprara GV, Barbaranelli C, Pastorelli C, Bandura A, Zimbardo PG (2000) Prosocial foundations of children's academic achievement. Psychol Sci 11(4): 302-306. 
16. Welsh M, Parke RD, Widaman K, Neil OR (2001) Linkages between children's social competence: A longitudinal analysis. Journal of School Psychology 39(6): 463-481.

17. Inglés CJ, Torregrosa MS, Hidalgo MD, Núñez JC, Castejón JL, et al. (2012) Validity evidence based on internal structure of scores on the Spanish version of the self-description questionnaire-II. Span J Psychol 15(1): 388-398.

18. Gilman R, Anderman EM (2006) The relationship between relative levels of motivation and intrapersonal, interpersonal, and academic functioning among older adolescents. Journal of School Psychology 44(5): 375-391.

19. Wentzel KR, Caldwell KA, McNamara C (2004) Friendships in middle school: Influences on motivation and school adjustment. Journal of Educational Psychology 96(2): 195-203.

20. Inglés CJ, Benavides G, Redondo J, Fernandez GJM, Esteban R, et al. (2009) Prosocial behaviour and academic achievement in Spanish students of compulsory secondary education. Anales de Psicología 25(1): 93-101.

21. Inglés CJ, González MAE, Fernández GJM, Torregrosa MS, Esteban RC (2012) Prosocial behavior and self-concept of Spanish students of compulsory secondary education. Revista de Psicodidáctica 17(1): 135158.

22. Inglés CJ, González MAE, Fernández GJM (2013) Prosocial behavior and learning strategies in a sample of Spanish students of compulsory secondary education. European Journal of Education and Psychology 6(1): 33-53.

23. Redondo J, Inglés CJ, Fernández GJM (2014) Prosocial behavior and academic self-attributions in compulsory secondary Education. Annals of Psychology 30(2): 482-489.

24. Inglés CJ, Fernández GJM, Castejón JL, Valle A, Delgado B, et al. (2009) Reliability and validity evidence of scores on the achievement goal tendencies questionnaire in a sample of Spanish students of compulsory secondary education. Psychology in the Schools 46(10): 1048-1060.

25. Borelli JL, Prinstein MJ (2006) Reciprocal, longitudinal associations among adolescents' negative feedback-seeking, depressive symptoms, and peer relations. J Abnorm Child Psychol 34(2): 159-169.

26. Smari J, Petursdottir G, Poersteindottir V (2001) Social anxiety and depression in adolescents in relation to perceived competence and situational appraisal. Journal of Adolescence 24(2): 199-207.

27. Delgado B, Esteban RC, Monteagudo MMC (2008) Causal attribution, academic self-concept, achievement goals, learning strategies and academic performance in students with and without social anxiety. In: Pienda GJA, Núñez JC (Eds.), Psychology and Education: A meeting place. University of Oviedo, Oviedo, Spain, pp. 997-1003.

28. Delgado B, Inglés CJ, Fernández GJM (2013) Social anxiety and selfconcept in adolescence. Revista de Psicodidáctica 18(1): 179-195.

29. Hannesdottir DK, Ollendick TH (2007) Social cognition and social anxiety among Icelandic schoolchildren. Child and Family Behavior Therapy 29: 43-58.

30. Cury F, Elliot A, Sarrazin P, Da Fonseca D, Rufo M (2002) The trichotomous achievement goal model and intrinsic motivation: a sequential meditational analysis. Journal of Experimental Social Psychology 38(5): 473-481.

31. Cantwell RH, Andrews B (2002) Cognitive and psychological factors underlying secondary school students' feelings towards group work. Educational Psychology 22(1): 75-91.

32. Van Amerigen M, Mancini C, Farvorden P (2003) The impact of anxiety disorders on educational achievement. Journal of Anxiety Disorders 17: 561-571.

33. Albers CA, Kratochwill TR, Glover TA (2007) Where are we and where do we go now? Universal screening for enhanced educational and mental health outcomes. Journal of School Psychology 45(2): 257-263.
34. Frey A, Ruchkin V, Martin A, Stone SM (2009) Adolescents in transition: School and family characteristics in the development of violent behaviours entering high school. Child Psychiatry and Human Development 40: 1-13.

35. Lounsbury JW, Sundstrom E, Loveland JM, Gibson LW (2003) Intelligence big five personality traits, and work drive as predictors of course grade. Personality and Individual Differences 35(6): 1231-1239.

36. Barry CM, Wentzel KR (2006) Friend influence on prosocial behavior: The role of motivational factors and friendship characteristics. Dev Psychol 42(1): 153-163.

37. Inglés CJ, Delgado B, García Fernández JM, Ruiz Esteban C, Díaz Herrero A (2010) Sociometric types and social interaction styles in a sample of Spanish adolescents. Spanish Journal of Psychology 13(2): 728-738.

38. Hayamizu T, Weiner B (1991) A test of Dweck's model of achievement goals as related to perceptions of ability. Journal of Experimental Education 59(3): 904-915.

39. Marsh HW (1992) SDQ II: Manual: Self research centre, University of Western Sydney, Australia.

40. Gilman R, Laughlin JE, Huebner ES (1999) Validation of the selfdescription questionnaire-II with an American sample. School Psychology International 20(3): 300-307.

41. Inderbitzen HM, Foster SL (1992) The teenage inventory of social skills: Development, reliability and validity. Psychological Assessment 4(4): 451-459.

42. Inglés CJ, Hidalgo MD, Méndez FX, Inderbitzen HM (2003) The teenage inventory of social skills: Reliability and validity of the Spanish translation. J Adolesc 26(4): 505-510.

43. Turner SM, Beidel DC, Dancu CV, Stanley MA (1989) An empirically derived inventory to measure social fears and anxiety: The social phobia and anxiety inventory. Psychological Assessment 1: 35-40.

44. Olivares J, López GLJ, Hidalgo MD, La Greca AM, Turner SM, et al. (2002) A pilot study on normative data for two social anxiety measures: The social phobia and anxiety inventory and the social anxiety for adolescents. International Journal of Clinical and Health Psychology 2(3): 467-476.

45. García López LJ, Olivares J, Hidalgo MD, Beidel DC, Turner SM (2001) Psychometric properties of the social phobia and anxiety inventory, the social anxiety scale for adolescents, the fear of negative evaluation scale and the social avoidance distress scale in an adolescent Spanish speaking population. Journal of Psychopathology and Behavioral Assessment 23(1): 51-59.

46. Clark DB, Turner SM, Beidel DC, Donovan JE, Kirisciand L, et al. (1994) Reliability and validity of the social phobia and anxiety inventory for adolescents. Psychological Assessment 6(2): 135-140.

47. De Maris A (2003) Logistic regression. In: Schinka JA, Velicer WF (Eds.), Research Methods in Psychology, John Wiley \& Sons, New Jersey, USA, pp. 509-532.

48. Hay I (2000) Gender self-concept profiles of adolescents suspended from high school. J Child Psychol Psychiatry 41: 345-352.

49. Morrison GM, Robertson L, Harding M (1998) Resilience factors that support the classroom functioning of acting out and aggressive students. Psychology in the Schools 35(3): 217-227.

50. Fordham K, Hinde SJ (1999) Shyness, friend quality and adjustment during middle childhood. J Child Psychol Psychiatry 40: 757-768.

51. Delgado B, Aparisi D, Fernández GJM, Sanmartín R, Redondo J, et al. (2018) Attributional styles in Spanish students of compulsory secondary education with high social anxiety self-reported. Revista Latinoamericana de Psicología 50(2).

52. Strahan E, Conger AJ (1998) Social anxiety and its effects on performance and perception. J Anxiety Disord 12(4): 293-305. 
53. Seifert TL (2004) Understanding student motivation. Educational Research 46(2): 138-149.

54. Ministry of Education and Science (2017) Basic data of the education in Spain in the academic year 2014/2015. Ministry of Education and Science, Madrid, Spain.

55. Torregrosa MS, Inglés CJ, Fernández GJM, Gázquez JJ, Herrero DA, et al.
(2012) Aggressive behavior among peers and academic performance in Spanish adolescents. Behavioral Psychology/Psicología Conductual 20(2): 263-280

56. Torregrosa MS, Inglés CJ, Fernández GJM, Valle A, Núñez JC (2012) Relations between aggressive behavior and academic goals: study with a sample of Spanish students of compulsory secondary education. Universitas Psychologyca 11(4): 1303-1315. 